\title{
The role of rapid endoscopy for high-risk patients with acute nonvariceal upper gastrointestinal bleeding
}

\author{
Laura E Targownik MD MSHS, Sanjay Murthy MD, Leila Keyvani MD, Shauna Leeson RN
}

\begin{abstract}
LE Targownik, S Murthy, L Keyvani, S Leeson. The role of rapid endoscopy for high-risk patients with acute nonvariceal upper gastrointestinal bleeding. Can J Gastroenterol 2007;21(7):425-429.
\end{abstract}

BACKGROUND: Performance of endoscopy within $24 \mathrm{~h}$ is recommended for patients with acute nonvariceal upper gastrointestinal bleeding (ANVUGIB). It is unknown whether performing endoscopy early within this $24 \mathrm{~h}$ window is beneficial for clinically high-risk patients.

METHODS: A retrospective review was performed to identify patients presenting to two tertiary care centres with ANVUGIB and either systolic blood pressure lower than $100 \mathrm{mmHg}$ or heart rate greater than 100 beats/min on presentation between 1999 and 2004 . Patients receiving endoscopy within $6 \mathrm{~h}$ (rapid endoscopy [RE]) were compared with patients undergoing endoscopy between $6 \mathrm{~h}$ and $24 \mathrm{~h}$ (early endoscopy [EE]). The primary outcome measure was the development of any adverse bleeding outcome (rebleeding, surgery for control of bleeding, in-hospital mortality or readmission within 30 days for ANVUGIB).

RESULTS: There were 169 patients who met the entry criteria (77 RE patients and $92 \mathrm{EE}$ patients). There was no significant difference in the development of any adverse bleeding outcomes between RE and EE patients (25\% RE versus 23\% EE, difference between groups $2 \%, 95 \% \mathrm{CI}-9 \%$ to $13 \%)$. Transfusion requirements and length of hospital stay also did not differ between the comparator groups. RE was not associated with fewer adverse outcomes, even after adjusting for confounders.

CONCLUSION: For clinically high-risk ANVUGIB patients, performing endoscopy within $6 \mathrm{~h}$ of presentation is no more effective than performing endoscopy between $6 \mathrm{~h}$ and $24 \mathrm{~h}$ after presentation. The role of RE in high-risk ANVUGIB patients requires further delineation in a prospective fashion.

Key Words: Endoscopy; Nonvariceal upper gastrointestinal bleeding; Process of care

\section{Le rôle de l'endoscopie rapide pour les patients à haut risque souffrant de saignement œsogastroduodénal non variqueux aigu}

HISTORIQUE : Il est recommandé d'effectuer une endoscopie dans les 24 heures chez les patients souffrant d'un saignement œsogastroduodénal non variqueux aigu (SOGDNVA). On ne sait pas s'il est bénéfique d'exécuter l'endoscopie avec diligence, dans une fenêtre de 24 heures, pour les patients cliniquement à haut risque.

MÉTHODOLOGIE : Une analyse rétrospective a permis de repérer les patients s'étant présentés à deux centres de soins tertiaires entre 1999 et 2004 parce qu'ils souffraient d'un SOGDNVA et dont la tension artérielle systolique était inférieure à $100 \mathrm{mmHg}$ ou dont la fréquence cardiaque était supérieure à 100 battements/min à la présentation. Les patients qui avaient subi une endoscopie dans les six heures (endoscopie rapide [ER]) étaient comparés aux patients l'ayant subi dans les six à 24 heures (endoscopie diligente [ED]). La mesure d'issue primaire était l'apparition d'un saignement indésirable (nouveau saignement, opération pour contrôler un saignement, mortalité en milieu hospitalier ou réhospitalisation dans les 30 jours suivant le SOGDNVA).

RÉSULTATS : Cent soixante-neuf patients respectaient les critères de participation (77 patients ayant subi une ER et 99, une ED). On n'a observé aucune différence significative dans l'apparition d'un saignement indésirable entre les patients ayant subi une ER ou une ED (25\% d'ER par rapport à $23 \%$ d'ED, différence entre les groupes de $2 \%, 95 \%$ IC -9 \% à $13 \%)$. Les besoins de transfusion et la durée de l'hospitalisation ne différaient pas entre les groupes comparateurs. L'ER ne s'associait pas à une diminution du nombre d'issues indésirables, même après rajustement compte tenu des variables confusionnelles.

CONCLUSION : Chez les patients atteints de SOGDNVA cliniquement à haut risque, l'endoscopie n'est pas plus efficace si elle est effectuée dans les six heures suivant la présentation qu'entre six et 24 heures après la présentation. Le rôle de l'ER chez les patients atteints d'un SOGDNVA à haut risque doit maintenant faire l'objet d'une délimitation prospective supplémentaire. cute nonvariceal upper gastrointestinal bleeding
(ANVUGIB) is a common indication for hospital admis-
sion in North America, with an incidence rate of 50 to 150 per
100,000 person-years (1-3). While most episodes of ANVUGIB
are self limited and uncomplicated, approximately $15 \%$ to $30 \%$
of patients develop subsequent complications, including
recurrent bleeding, which has been shown to be highly predictive
of in-hospital mortality (4,5). Overall, $5 \%$ to $10 \%$ of persons admitted with ANVUGIB die from further bleeding or from decompensation of concomitant medical conditions $(1-3,6,7)$.

It is currently recommended that patients presenting with signs and symptoms of ANVUGIB undergo endoscopy within $24 \mathrm{~h}$ of presentation to hospital $(8,9)$. Endoscopy performed within this timeframe may decrease the likelihood of patients requiring blood transfusion and may also decrease the length of hospital stay in high-risk patients (10). Furthermore, early

Section of Gastroenterology, Department of Internal Medicine, University of Manitoba, Winnipeg, Manitoba

Correspondence: Dr Laura Targownik, 805G-715 McDermot Avenue, Winnipeg, Manitoba R3E 3P4. Telephone 204-789-3567,

fax 204-789-3972,e-mail targowni@cc.umanitoba.ca

Received for publication August 24, 2006. Accepted September 25, 2006 
TABLE 1

Calculation of pre-endoscopic Rockall score

\begin{tabular}{lcccc}
\hline & \multicolumn{4}{c}{ Score } \\
\cline { 2 - 5 } & $\mathbf{0}$ & $\mathbf{1}$ & $\mathbf{2}$ & $\mathbf{3}$ \\
\hline Age, years & $<60$ & $60-79$ & $\geq 80$ & - \\
Shock & & & & \\
HR, beats/min & $<100$ & - & $>100$ & - \\
SBP, mmHg & $>100$ & $>100$ & $<100$ & - \\
Comorbidity & None & & IHD, CHF, & $\begin{array}{c}\text { Renal failure, } \\
\text { any major } \\
\text { liver failure, } \\
\end{array}$ \\
& & & comorbidity & $\begin{array}{l}\text { metastatic } \\
\text { malignancy }\end{array}$ \\
& & & & mats
\end{tabular}

CHF Congestive heart failure; HR Heart rate; IHD Ischemic heart disease; SBP Systolic blood pressure

endoscopy may be useful in identifying patients who are at low risk of developing recurrent bleeding and who may then be safely managed as outpatients (11-13).

While there is generally agreement among providers on the utility of endoscopy within $24 \mathrm{~h}$ of hospital presentation, it may be more beneficial to perform endoscopy even sooner following the initial presentation, especially if the patient presents with signs of hemodynamic instability. EE may allow for better control of active hemorrhage and initiation of early preventive treatment of high-risk nonbleeding lesions, potentially decreasing transfusion requirements and the risk of recurrent bleeding and other complications. The caveat is that the earlier the endoscopy is performed, the greater the likelihood of finding high-risk stigmata on endoscopy (14), thereby increasing the proportion of patients who require endoscopic hemostasis and prolonged inpatient observation. Furthermore, the need for endoscopy shortly after presentation often requires endoscopists to perform procedures outside of regular working hours and also necessitates that high-risk patients be admitted or transferred to centres where endoscopic services are immediately available. Overall, this option would likely place a considerable burden on both caregivers and hospitals.

To date, the role for performing endoscopy earlier within the initial $24 \mathrm{~h}$ window for patients with evidence of hemodynamic instability of presentation has not been adequately evaluated. Showing incremental benefit with endoscopy performed within $6 \mathrm{~h}$ of presentation in patients with hemodynamic instability may promote the use of more rapid endoscopy as the standard of care in such patients. Therefore, we sought to evaluate the role of performing endoscopy within $6 \mathrm{~h}$ of hospital presentation in ANVUGIB patients with evidence of hemodynamic instability.

\section{Patient identification}

\section{METHODS}

A retrospective chart review was performed on all patients admitted through the emergency department of one of two tertiary care centres in Winnipeg, Manitoba, between April 1999 and March 2004. Both tertiary care centres are affiliated with the University of Manitoba. All gastroenterology fellows and all residents perform rotations at both hospitals, and neither hospital has a specific caremap to guide the triage and management of patients presenting with ANVUGIB. Therefore, there is unlikely to be a systematic difference in the process of care of ANVUGIB patients between the two centres.
Patients who were admitted with a primary admitting diagnosis consistent with ANVUGIB were included. To accurately identify patients with ANVUGIB, a list of International Classification of Diseases, Ninth Revision codes were used, which has been previously validated extensively (15). Only those identified patients who had evidence of acute upper gastrointestinal bleeding on presentation, as manifested by hematemesis or melena with visualization of a nonvariceal culprit lesion in the upper gastrointestinal tract, or hematochezia, with identification of a suitable nonvariceal upper gastrointestinal lesion and no definite bleeding source identified on colonoscopy or sigmoidoscopy, were included. The study population was limited to patients who had either hypotension (defined as systolic blood pressure lower than $100 \mathrm{mmHg}$ ) or tachycardia (heart rate faster than 100 beats/min) on their initial assessment of vital signs.

Patients were excluded if they had evidence of only chronic gastrointestinal bleeding, such as iron deficiency anemia or stools positive for occult blood. Patients were also excluded from the study if they were found to have gastrointestinal bleeding related to portal hypertension, if they were transferred from another health care institution more than $6 \mathrm{~h}$ after their initial presentation or if they did not undergo endoscopy within $24 \mathrm{~h}$ of their initial presentation. The study protocol was approved by the University of Manitoba research ethics boards and by the internal research committees of both participating hospitals.

\section{Data abstraction}

Data were abstracted by three researchers (LK, SM, SL) who were specifically trained to identify suitable patients and to accurately transcribe data from the hospital record onto standardized abstraction charts. Data were collected with regard to patient demographics, severity of presentation via clinical Rockall score (Table 1) (1), pre-existing patient comorbidities and medication use, and pre-endoscopic management with specific attention to the timing and dose of pre-endoscopic acid-inhibiting medications. Data were also abstracted describing endoscopic management, including time of performance, the endoscopic diagnosis and the presence of high-risk stigmata (including arterial bleeding, nonbleeding visible vessel and adherent clot), as well as whether endoscopic hemostasis was undertaken. Data describing medication use following performance of endoscopy, as well as the overall course in hospital until discharge, with specific attention to recurrent hemorrhage and need for surgery for control of recurrent hemorrhage, were gathered. The medical record was reviewed for evidence of readmission to hospital within 30 days of discharge.

\section{Assessment of outcomes}

All enrolled patients were separated into one of two groups based on whether they had received rapid endoscopy (RE), defined as endoscopy performed within $6 \mathrm{~h}$ of initial presentation to hospital, or early endoscopy (EE), defined as endoscopy performed after $6 \mathrm{~h}$ but within $24 \mathrm{~h}$ of presentation to hospital.

The primary outcome was a difference between RE and EE patients in the composite end point of incidence of in-hospital rebleeding, surgery for control of rebleeding, in-hospital mortality and readmission to hospital within 30 days of discharge for ANVUGIB. Rebleeding was defined as hematemesis following initial endoscopy, documented melena or hematochezia following endoscopy if associated with a drop in hemoglobin of more than $20 \mathrm{~g} / \mathrm{L}$ from the first postendoscopy hemoglobin measurement, recurrent melena after documentation of nonmelenic stool, or the presence of active bleeding or an ulcer with high-risk stigmata on 
a repeat upper endoscopy for any reason within the same hospital admission. Other outcomes of interest included the incidence of high-risk stigmata at the time of endoscopy, the incidence of endoscopic hemostasis at initial endoscopy, the overall length of hospital stay, as well as the mean number of units of packed red blood cells transfused both overall and more than $24 \mathrm{~h}$ after the performance of the initial endoscopy.

\section{Data integrity and statistics}

One of the investigators (LET) manually checked the completed data abstraction forms to assess the provided information for inconsistencies. An automated check was then performed after data entry had been completed for each subject file. Missing or inconsistent data were resolved through a review of the medical record. Two-tailed Student's $t$ tests and Fisher's exact tests were used to compare means and proportions of appropriate data from the two sites. Non-normally distributed data were analyzed with the Wilcoxon's signed rank test. Multiple logistic regression analysis was performed using NCSS 2004 (NCSS, USA) to account for the effect of potentially confounding variables, including age, sex, receipt of pre-endoscopic proton pump inhibitors (PPIs), clinical Rockall score of five or greater, presence of high-risk stigmata on endoscopy and performance of endoscopic hemostasis. A twosided $\mathrm{P}$ value less than 0.05 was considered to be statistically significant. It was estimated that 394 patients would need to be included to detect a $40 \%$ reduction in adverse outcomes between groups with a power of $80 \%$, assuming a baseline rebleeding rate of $25 \%$ and equal sizes of the comparator groups.

\section{RESULTS}

There were 552 patients admitted to the two participating hospitals with ANVUGIB between April 1999 and March 2004. Of these, 169 had either hypotension or tachycardia on presentation and underwent endoscopy within $24 \mathrm{~h}$ of presentation. Seventy-seven patients underwent RE, while 92 received EE. This sample size provides a power of $37.2 \%$ to exclude a decline in the rate of adverse outcomes from $25 \%$ to $15 \%$.

A description of the baseline characteristics of included patients is shown in Table 2. RE patients were evenly matched in terms of risk of adverse outcomes, as suggested by their clinical Rockall scores. Patients in the RE group were statistically more likely to have either active bleeding, a nonbleeding visible vessel or an adherent clot than patients in the EE group (57\% versus $37 \%, \mathrm{P}=0.012$ ), as well as to have undergone endoscopic hemostasis ( $53 \%$ versus $37 \%, \mathrm{P}=0.043$ ). Patients in the RE group were less likely to have received PPI therapy before endoscopy ( $9 \%$ versus $41 \%, \mathrm{P}<0.001$ ), but the median time to the initial PPI dose was no different between the two groups, (7.6 h RE versus $10.5 \mathrm{~h} \mathrm{EE}, \mathrm{P}>0.2$ ). All other tabulated parameters were statistically similar between the two groups.

The primary outcome of incidence of overall adverse events as previously defined was not statistically different between the two groups (25\% RE versus $23 \% \mathrm{EE}, \mathrm{P}>0.2)$. There were no significant differences in the rates of any of the individual adverse outcomes between the two groups (Figure 1). Median length of hospital stay was four days in both groups $(\mathrm{P}=0.27)$. Transfusion requirements between the two groups were similar (3.3 units $\mathrm{RE}$ versus 2.9 units $\mathrm{EE}, \mathrm{P}>0.2$ ).

In multiple logistic regression analysis, RE was associated with a nonsignificant decrease in the likelihood of developing an adverse gastrointestinal outcome, with an OR of $1.16(95 \%$ CI 0.53 to 2.52 ). Similarly, no other variables included in the
TABLE 2

Description of the comparator groups

\begin{tabular}{|c|c|c|c|}
\hline & $\begin{array}{c}\text { Rapid } \\
\text { endoscopy* }\end{array}$ & $\begin{array}{c}\text { Early } \\
\text { endoscopy }\end{array}$ & $P$ \\
\hline \multicolumn{4}{|l|}{ Demographics } \\
\hline $\mathrm{n}$ & 77 & 92 & \\
\hline Age (years), mean \pm SD & $63.6 \pm 15.8$ & $62.6 \pm 18.6$ & $>0.2$ \\
\hline Females, \% & 38 & 41 & $>0.2$ \\
\hline \multicolumn{4}{|l|}{ Baseline clinical characteristics } \\
\hline $\mathrm{SBP}(\mathrm{mmHg})$, mean $\pm \mathrm{SD}$ & $112 \pm 30.4$ & $116 \pm 28.7$ & $>0.2$ \\
\hline $\mathrm{DBP}(\mathrm{mmHg})$, mean $\pm \mathrm{SD}$ & $64 \pm 18.8$ & $69 \pm 20.0$ & $>0.2$ \\
\hline $\mathrm{HR}$ (beats/min), mean $\pm \mathrm{SD}$ & $111 \pm 16.8$ & $107 \pm 20.2$ & 0.11 \\
\hline $\mathrm{SBP} \leq 100 \mathrm{mmHg}, \%$ & 42 & 37 & $>0.2$ \\
\hline $\mathrm{HR}>100$ beats $/ \mathrm{min}, \%$ & 82 & 76 & $>0.2$ \\
\hline $\mathrm{HgB}$ on presentation $(\mathrm{g} / \mathrm{L})$, mean $\pm \mathrm{SD}$ & $92.6 \pm 25.2$ & $90.2 \pm 30.5$ & $>0.2$ \\
\hline INR $>1.5, \%$ & 16 & 23 & $>0.2$ \\
\hline Platelets $<50 \times 10^{9} / \mathrm{L}, \%$ & 4 & 3 & $>0.2$ \\
\hline Urea/creatinine ratio, mean \pm SD & $161 \pm 83$ & $150 \pm 84$ & $>0.2$ \\
\hline \multicolumn{4}{|l|}{ Pre-endoscopic Rockall score } \\
\hline Mean \pm SD & $3.2 \pm 1.8$ & $3.3 \pm 1.8$ & $>0.2$ \\
\hline Score $\geq 5, \%$ & 31 & 35 & $>0.2$ \\
\hline \multicolumn{4}{|l|}{ Medications at presentation, $\mathrm{n}$} \\
\hline Acetylsalicylic acid & 29 & 21 & $>0.2$ \\
\hline NSAIDs (including COX2 inhibitors) & 21 & 25 & $>0.2$ \\
\hline Corticosteroids & 1 & 4 & $>0.2$ \\
\hline Warfarin & 8 & 9 & $>0.2$ \\
\hline $\mathrm{H}_{2} \mathrm{RAs}$ & 12 & 8 & $>0.2$ \\
\hline PPIs & 13 & 10 & $>0.2$ \\
\hline Significant pre-existing comorbidities, $\mathrm{n}$ & 45 & 47 & $>0.2$ \\
\hline \multicolumn{4}{|l|}{ Endoscopic findings, \% } \\
\hline Gastric ulcer/erosions & 30 & 35 & $>0.2$ \\
\hline Duodenal ulcer/erosions & 43 & 34 & $>0.2$ \\
\hline High-risk endoscopic stigmata & 57 & 37 & 0.012 \\
\hline Active arterial bleeding & 17 & 13 & $>0.2$ \\
\hline Nonbleeding visible vessel & 17 & 12 & $>0.2$ \\
\hline Adherent clot & 27 & 15 & 0.032 \\
\hline Undergoing endoscopic hemostasis & 53 & 37 & 0.043 \\
\hline \multicolumn{4}{|l|}{ Process of care measures } \\
\hline Median time to first PPI (oral or IV), $\mathrm{h}$ & 7.6 & 10.5 & $>0.2$ \\
\hline Interquartile range & $4.6-16.8$ & $4.7-16.9$ & - \\
\hline $\begin{array}{l}\text { Receiving pre-endoscopic } \\
\text { PPI (oral or IV), } \%\end{array}$ & 9 & 41 & $<0.001$ \\
\hline Receiving postendoscopic IV PPIs, \% & 37 & 23 & 0.065 \\
\hline
\end{tabular}

${ }^{*}$ Endoscopy received within $6 \mathrm{~h}$ of patient arrival at the hospital, tEndoscopy received $6 \mathrm{~h}$ to $24 \mathrm{~h}$ after patient arrival at the hospital. COX2 Cyclooxygenase-2; $D B P$ Diastolic blood pressure; $\mathrm{H}_{2} R A$ s Histamine 2-receptor antagonists; $\mathrm{HgB}$ Hemoglobin; HR Heart rate; INR International normalized ratio; IV Intravenous; NSAIDs Nonsteroidal anti-inflammatory drugs; PPI Proton pump inhibitor; SBP Systolic blood pressure

analysis predicted a statistical difference in overall adverse outcomes between the two groups.

\section{DISCUSSION}

Our findings demonstrated that there is no difference in the rate of overall adverse outcomes when patients presenting with high-risk ANVUGIB are managed with either RE or EE. These findings suggest that endoscopy can be safely delayed 


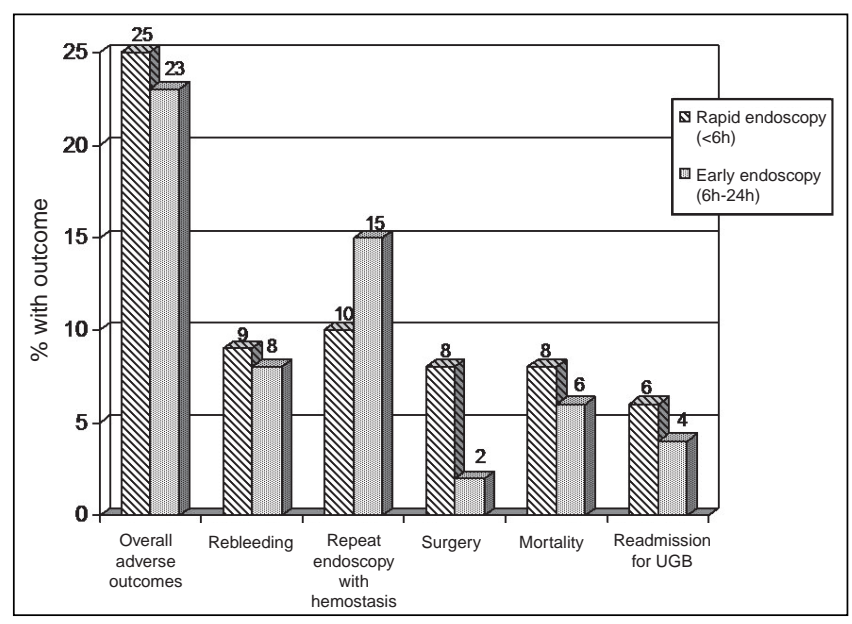

Figure 1) Comparison of the probability of adverse outcomes between acute nonvariceal upper gastrointestinal bleeding (UGB) patients undergoing rapid endoscopy versus early endoscopy. P>0.10 for all comparisons

beyond $6 \mathrm{~h}$ in most ANVUGIB patients who have either hypotension or tachycardia on presentation. This finding has important implications for situations in which endoscopic services may not be immediately available, such as in remote centres that may not have endoscopic services or in otherwise equipped facilities outside of regular working hours.

While there have been numerous studies detailing the benefits of performing endoscopy in high-risk ANVUGIB patients within the first $24 \mathrm{~h}$ following presentation to hospital $(16,17)$, there are relatively limited data to support the use of endoscopy earlier within this $24 \mathrm{~h}$ window in clinically highrisk patients. Spiegel et al (9) performed a systematic review of the literature to evaluate outcomes associated with performance of early endoscopy in high-risk clinical patients, and found only one citation published in abstract form that compared endoscopy performed at an earlier time within the $24 \mathrm{~h}$ window with endoscopy performed later but within $24 \mathrm{~h}$. This study showed no difference in rebleeding rates between patients undergoing endoscopy within $6 \mathrm{~h}$, from $6 \mathrm{~h}$ to $12 \mathrm{~h}$, and from $12 \mathrm{~h}$ to $24 \mathrm{~h}$ (18). However, the study contained only 112 patients overall and was thus also significantly underpowered to detect a clinically meaningful difference between the treatment groups. More recently, Bjorkman et al (13) performed a randomized trial comparing rapid endoscopy, defined as endoscopy within $6 \mathrm{~h}$, with regular endoscopy performed within $48 \mathrm{~h}$ and also found no difference in outcomes between the two groups. However, this study specifically excluded highrisk patients and enrolled only 93 patients.

While intuitively it is expected that more rapid endoscopy would be associated with improved outcomes, there are a number of factors that may explain why RE may not be superior to $\mathrm{EE}$ in preventing further gastrointestinal complications. First, if the endoscopy is performed while bleeding is ongoing or soon after the initial bleeding has ceased, there may be a large amount of fresh blood or blood clots, which may obscure the bleeding site, making performance of endoscopic hemostasis difficult or impossible (19). Although some studies suggest that provision of promotility agents before endoscopy may improve visualization of lesions at the time of endoscopy $(20,21)$, promotility agents are not routinely used before endoscopy at our study centres. Second, the time between active bleeding and endoscopy allows for a previously bleeding lesion to commence healing, which may downstage a lesion from one that requires endoscopic hemostasis to a low-risk lesion that can be managed with pharmacological therapy alone (14). This is reflected by the significantly higher rates of high-risk stigmata and endoscopic hemostasis performed in the RE cohort in our study. While endoscopic hemostasis dramatically decreases the risk of rebleeding of high-risk lesions, the risk still remains higher than that associated with a clean-based ulcer (22-24).

Given the burden on health care resources that would result from all high-risk patients with ANVUGIB receiving endoscopy within $6 \mathrm{~h}$ of presentation to any health care facility, we decided a priori that RE would have to decrease the rate of adverse outcomes from an expected baseline rate of $25 \%$ to $15 \%$ for this practice to be widely adopted (ie, a $40 \%$ relative reduction in adverse events). Unfortunately, despite including all eligible patients with ANVUGIB over a five-year period, we were not able to include a sufficient number of patients to reach our desired sample size. Other studies of EE have also had similar problems with enrolling sufficient numbers of patients. Still, we determined with $95 \%$ confidence that there is, at best, a $9 \%$ difference in adverse outcomes in favour of RE and, at worst, a 13\% difference in adverse outcomes in favour of EE. Therefore, performing RE as a matter of policy for all clinically high-risk patients is not necessary, although clinicians should still consider performing RE on a case-by-case basis as dictated by their clinical acumen.

We also determined that patients who received RE were much less likely to have received a PPI before the endoscopy than patients who underwent EE. This was likely due to the fact that patients receiving RE may not have had ample opportunity to receive their initial dose of a PPI before the performance of endoscopy. Recent data suggest that preendoscopic administration of a PPI may decrease the risk of subsequent gastrointestinal complications (25). Platelet aggregation and hemostasis best occur in a nonacidic milieu, and thus, it is postulated that endoscopic therapy may be more efficacious if performed in a PPI-induced nonacidic milieu (26). This may partially explain the lack of additional benefit seen in patients undergoing endoscopy within $6 \mathrm{~h}$ of presentation. Conversely, the overall time to initial receipt of PPI therapy was not significantly different between the two groups.

The present study does have a number of noteworthy limitations that warrant further discussion. Because we were not able to prospectively assess patients to definitively determine the presence of recurrent gastrointestinal bleeding, we were forced to rely on data from patient charts, in which the presence of rebleeding may not be explicitly stated. Therefore, it is possible that patients who developed recurrent bleeding in-hospital may have been misclassified as nonbleeders and vice versa. In an effort to minimize this misclassification, we used a definition of rebleeding that has been used in other retrospective gastrointestinal bleeding studies. Also, because patients were not randomly assigned to either the treatment or the control groups, it is possible that there were unmeasured factors that might have stimulated a patient undergoing rapid endoscopy on presentation to hospital. However, we found no significant differences in demographics, pre-existing medical conditions, previously used medication and severity of the initial presentation between patients who received 
endoscopy within $6 \mathrm{~h}$ of presentation and those undergoing endoscopic investigation between $6 \mathrm{~h}$ and $24 \mathrm{~h}$ after presentation. Furthermore, the mean clinical Rockall score, an extensively validated measure of risk of rebleeding, was not significantly different between the two groups, and there were no statistically significant differences in any of the other individual variables that may predict an adverse outcome, including the presence of advanced age, anemia, coagulopathy or the use of anticoagulants. Moreover, a logistic regression adjusting for potential confounders did not demonstrate a relationship between timing of endoscopy and improved outcomes. However, we do recognize that there may still be unmeasured or intangible factors associated with adverse gastrointestinal outcomes that may have been more prevalent in the RE group, potentially biasing our findings. Therefore, the findings in our study should ideally be confirmed in a prospective fashion, in which unmeasured variables that may

\section{REFERENCES}

1. Rockall TA, Logan RF, Devlin HB, Northfield TC. Incidence of and mortality from acute upper gastrointestinal haemorrhage in the United Kingdom. Steering Committee and members of the National Audit of Acute Upper Gastrointestinal Haemorrhage. BMJ 1995;311:222-6.

2. Vreeburg EM, Snel P, de Bruijne JW, Bartelsman JF, Rauws EA, Tytgat GN. Acute upper gastrointestinal bleeding in the Amsterdam area: Incidence, diagnosis, and clinical outcome. Am J Gastroenterol 1997;92:236-43.

3. Longstreth GF. Epidemiology of hospitalization for acute upper gastrointestinal hemorrhage: A population-based study. Am J Gastroenterol 1995;90:206-10.

4. Terdiman JP, Ostroff JW. Risk of persistent or recurrent and intractable upper gastrointestinal bleeding in the era of therapeutic endoscopy. Am J Gastroenterol 1997;92:1805-11.

5. Fleischer D. Etiology and prevalence of severe persistent upper gastrointestinal bleeding. Gastroenterology 1983;84:538-43.

6. Lewis JD, Bilker WB, Brensinger C, Farrar JT, Strom BL. Hospitalization and mortality rates from peptic ulcer disease and GI bleeding in the 1990s: Relationship to sales of nonsteroidal anti-inflammatory drugs and acid suppression medications. Am J Gastroenterol 2002;97:2540-9.

7. Barkun A, Sabbah S, Enns R, et al; RUGBE Investigators. The Canadian Registry on Nonvariceal Upper Gastrointestinal Bleeding and Endoscopy (RUGBE): Endoscopic hemostasis and proton pump inhibition are associated with improved outcomes in a real-life setting. Am J Gastroenterol 2004;99:1238-46.

8. Barkun A, Bardou M, Marshall JK; Nonvariceal Upper GI Bleeding Consensus Conference Group. Consensus recommendations for managing patients with nonvariceal upper gastrointestinal bleeding. Ann Intern Med 2003;139:843-57.

9. Spiegel BM, Vakil NB, Ofman JJ. Endoscopy for acute nonvariceal upper gastrointestinal tract hemorrhage: Is sooner better? A systematic review. Arch Intern Med 2001;161:1393-404.

10. Cooper GS, Chak A, Way LE, Hammar PJ, Harper DL, Rosenthal GE. Early endoscopy in upper gastrointestinal hemorrhage: Associations with recurrent bleeding, surgery, and length of hospital stay. Gastrointest Endosc 1999;49:145-52.

11. Longstreth GF, Feitelberg SP. Successful outpatient management of acute upper gastrointestinal hemorrhage: Use of practice guidelines in a large patient series. Gastrointest Endosc 1998;47:219-22.

12. Rockall TA, Logan RF, Devlin HB, Northfield TC. Selection of patients for early discharge or outpatient care after acute upper gastrointestinal haemorrhage. National Audit of Acute Upper Gastrointestinal Haemorrhage. Lancet 1996;347:1138-40. affect outcomes can be randomly and equally assigned between groups.

\section{CONCLUSION}

Performance of endoscopy within $6 \mathrm{~h}$ of presentation does not appear to be associated with a significant decrease in the risk of developing adverse gastrointestinal outcomes and may lead to prolonged hospital stays in clinically high-risk patients. Rapid endoscopy may still be considered on a case-by-case basis. Further prospective studies need to be performed to delineate situations in which the performance of rapid endoscopy should be strongly considered.

FUNDING: The present study is partially funded through an unrestricted grant provided by Altana Pharmaceuticals Canada, Inc. Dr Targownik is supported by the Rudy Falk Clinician Scientist Award.
13. Bjorkman DJ, Zaman A, Fennerty MB, Lieberman D, Disario JA, Guest-Warnick G. Urgent vs elective endoscopy for acute non-variceal upper-GI bleeding: An effectiveness study. Gastrointest Endosc 2004;60:1-8.

14. Lau JY, Chung SC, Leung JW, Lo KK, Yung MY, Li AK. The evolution of stigmata of hemorrhage in bleeding peptic ulcers: A sequential endoscopic study. Endoscopy 1998;30:513-8.

15. Cooper GS, Chak A, Lloyd LE, Yurchick PJ, Harper DL, Rosenthal GE. The accuracy of diagnosis and procedural codes for patients with upper GI hemorrhage. Gastrointest Endosc 2000;51:423-6.

16. Lee JG, Turnipseed S, Romano PS, et al. Endoscopy-based triage significantly reduces hospitalization rates and costs of treating upper GI bleeding: A randomized controlled trial. Gastrointest Endosc 1999;50:755-61.

17. Hay JA, Maldonado L, Weingarten SR, Ellrodt AG. Prospective evaluation of a clinical guideline recommending hospital length of stay in upper gastrointestinal tract hemorrhage. JAMA 1997;278:2151-6.

18. Choudari CP, Palmer KR. Timing of endoscopy for severe peptic ulcer hemorrhage: Out of hours emergency endoscopy is unnecessary. Gastroenterology1993;104:A55. (Abst)

19. Choudari CP, Rajgopal C, Elton RA, Palmer KR. Failures of endoscopic therapy for bleeding peptic ulcer: An analysis of risk factors. Am J Gastroenterol 1994;89:1968-72.

20. Coffin B, Pocard M, Panis Y, et al; Groupe des endoscopistes de garde a l'AP-HP. Erythromycin improves the quality of EGD in patients with acute upper GI bleeding: A randomized controlled study. Gastrointest Endosc 2002;56:174-9.

21. Frossard JL, Spahr L, Queneau PE, et al. Erythromycin intravenous bolus infusion in acute upper gastrointestinal bleeding: A randomized, controlled, double-blind trial. Gastroenterology 2002;123:17-23. (Erratum in 2002;123:2162).

22. Storey DW, Bown SG, Swain CP, Salmon PR, Kirkham JS, Northfield TC. Endoscopic prediction of recurrent bleeding in peptic ulcers. N Engl J Med 1981;305:915-6.

23. Laine L, Peterson WL. Bleeding peptic ulcer. N Engl J Med 1994;331:717-27.

24. Cook DJ, Guyatt GH, Salena BJ, Laine LA. Endoscopic therapy for acute nonvariceal upper gastrointestinal hemorrhage: A meta-analysis. Gastroenterology 1992;102:139-48.

25. Keyvani LE, Krishnamurthy S, Targownik LE. The relation between the choice of pre-endoscopic acid inhibition and outcomes in patients with acute non-variceal gastrointestinal bleeding (ANVUGIB). Aliment Pharmacol Ther. (In press)

26. Chiverton SG, Hunt RH. Relationship between inhibition of acid secretion and healing of peptic ulcers. Scand J Gastroenterol Suppl 1989;166:43-7. 


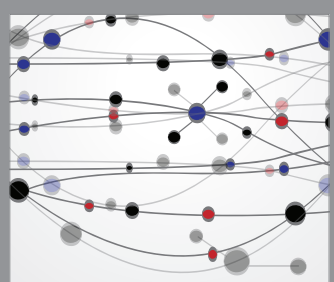

The Scientific World Journal
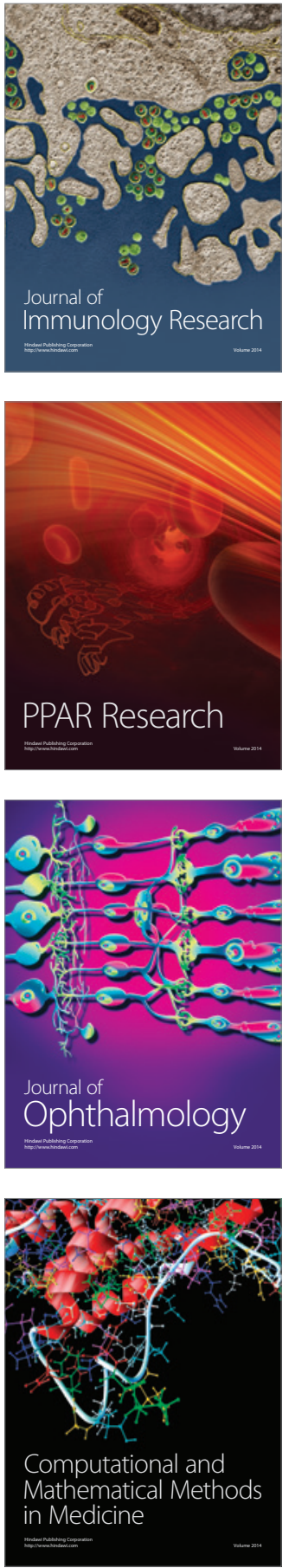

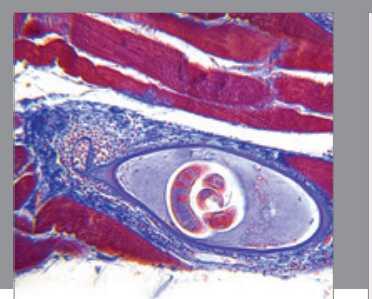

Gastroenterology Research and Practice

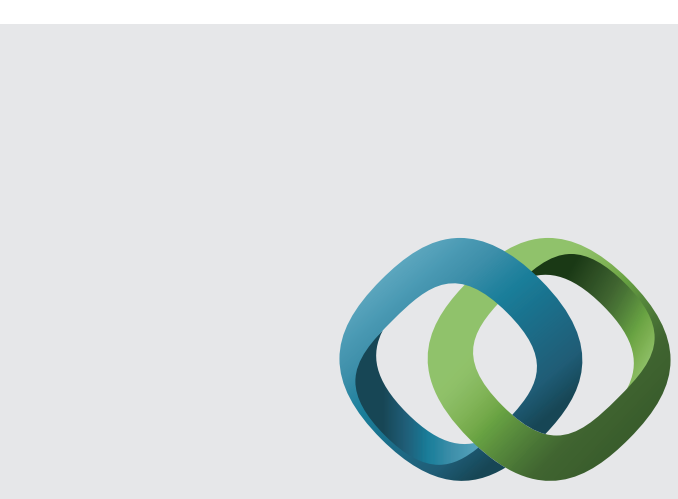

\section{Hindawi}

Submit your manuscripts at

http://www.hindawi.com
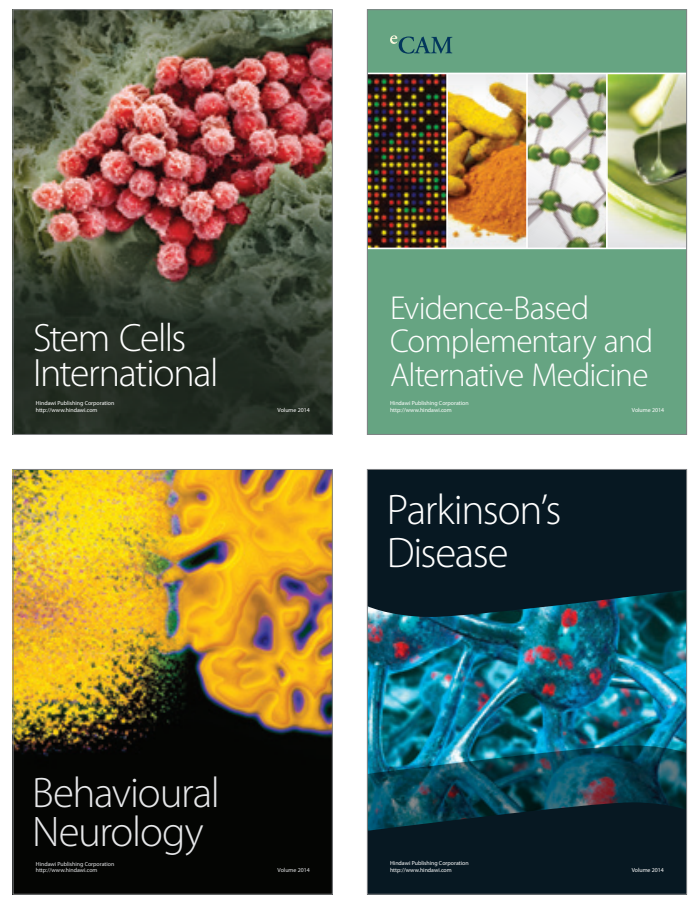
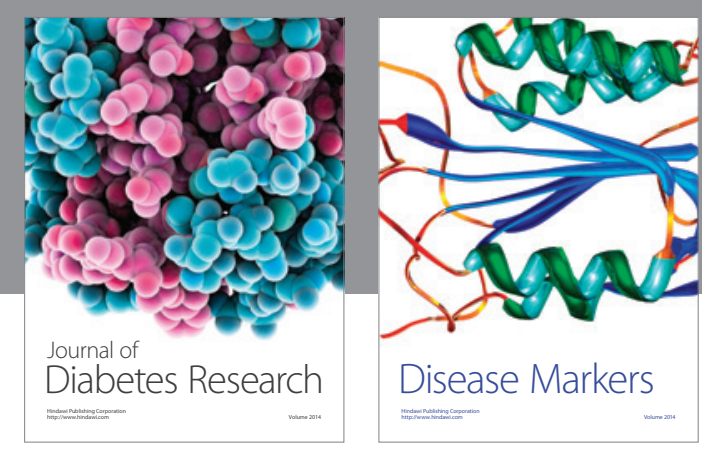

Disease Markers
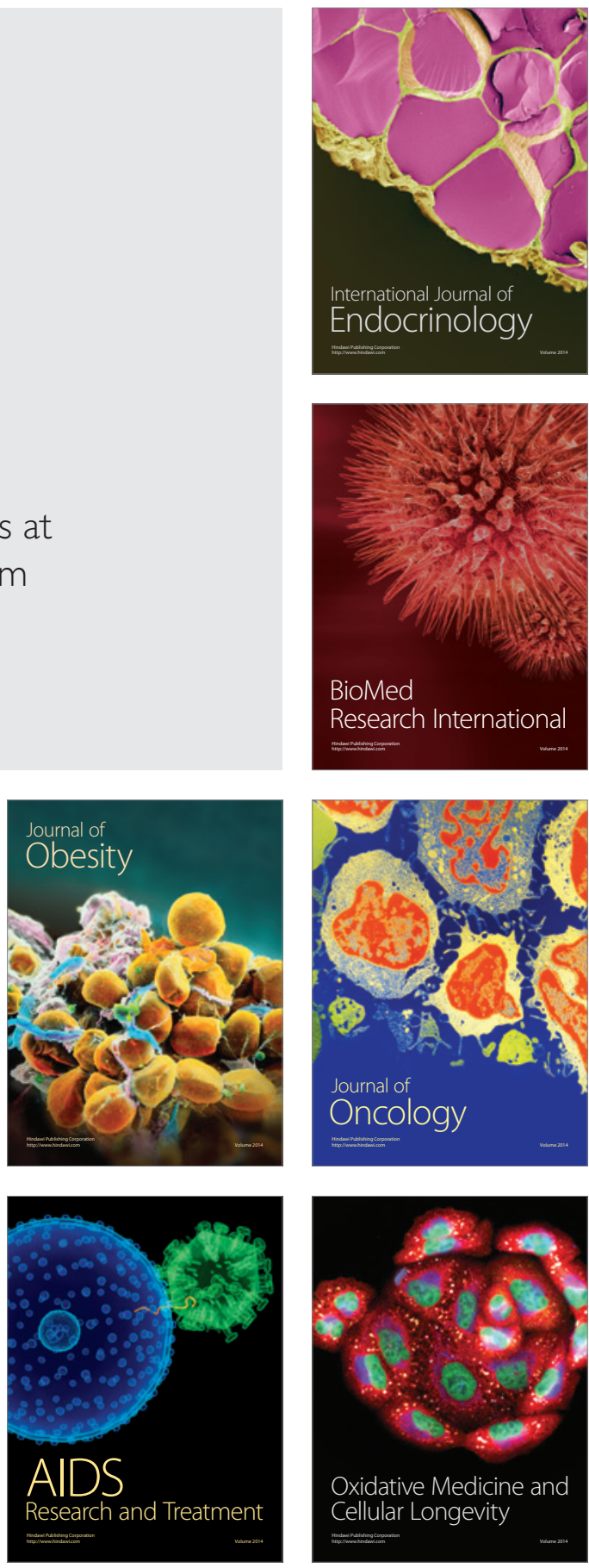